\title{
Review of modern military insensitive high explosives
}

\begin{abstract}
Kerim Krnjić ${ }^{1}$
${ }^{1}$ Mechanical Engineering Faculty, University of Sarajevo, Bosnia and Herzegovina

*Corresponding author: krnjickerim15@gmail.com

OThenuthor

2021.

Published by

ARDA.

Abstract

In the last twenty years, high energetic materials have changed significantly. Several factors have influenced the development of these materials, which include new operational requirements such as insensitive ammunition (IM), as well as factors in the availability of new materials and new production techniques, safety assessment, and modeling. All this enables more efficient use of materials and a more detailed understanding of the processes involved in the application of new technologies. This work presents new insensitive secondary high explosives such as TATB, FOX-7, GUDN, NTO, and others that are in different stages of development. A review of these explosives is given and their stability, reliability, and specific application are described. Energy materials are known to be chemical compounds or mixtures that contain significant amounts of energy and it has been shown that successful design of new energetic materials with customized performance properties and increased stability is possible. The properties of new insensitive energetic materials must be further researched and improved before they can be used in new or existing systems. Insensitive ammunition testing is a vital component of many national IM programs. The international community has established requirements for testing the insensitivity of materials and developed six unique tests based on testing the response of the material to the effects of heat, impact, or shock.
\end{abstract}

Keywords: insensitive ammunition, FOX-7, FOX-12, TATB, NTO, tests for insensitive ammunition.

\section{Introduction}

There are many factors that must be taken into account when assessing newly developed insensitive materials. When developing these materials, it is necessary to harmonize the requirements for high performance and reduced sensitivity, while considering the availability and price of the product. The search for the promising high-energy materials during the last decade has led to the discovery of a vast number of energetic oxidizers, fuels and explosives for their possible use as an energetic ingredient in propellants/explosives formulations. Exploitation of structure property relationships, coupled with the use of computer codes to predict the energetic properties from molecular structure, has led to the development of new energetic materials with increased performance, reduced sensitivity to external stimuli and or enhanced chemical and thermal stability. The other important properties which decide the fate of newly synthesized energetic material for its application in propellant and explosive formulations are its chemical compatibility with other ingredients in the formulation, less toxicity, stable physical form and ease of its handling. All these properties are compared

This work is licensed under a Creative Commons Attribution License(https://creativecommons.org/licenses/by/4.0/) that allows others (c) (i) to share and adapt the material for any purpose (even commercially), in any medium with an acknowledgement of the work's authorship and initial publication in this journal. 
with the properties of known benchmark energetic materials which are currently in use in propellant or explosive formulations. High energy materials research area received less attention from the energetic materials scientists in the past. This may be attributed to the risks and hazards associated with the research investigations. There has been progress in the synthesis and development of new energetic compounds in recent years. The other category of nitro compounds emerging as key ingredients for propellant and explosive formulations are tetrazoles, triazines, tetrazines, compounds of metallic salts of hydrazines, carbohydrazines and polymeric binders containing azo, nitro-, nitroxy- groups in the backbones. New requirements such as reduction of the vulnerability of combat platforms, stealth characteristics, and increased demand to achieve higher energetics in terms of specific impulse and performance coupled with environmental issues have forced the researchers to produce novel energetic materials. To develop a new energetic material, it is essential to consider the factors such as indigenous availability of starting materials, ease of its preparation, purity of energetic material and its cost effectiveness. One of the approaches used to synthesize insensitive explosives is basically in the maximum possible percentage of nitrogen in energy materials[1].

A brief overview of certain low-sensitivity energy substances is given. A small number of the presented compounds are already in commercial application, and most are in the research phase. Some of the most interesting new energetic materials are: TATB, FOX-7, FOX-12, TEX, NTO, RS-RDX, ANTA, DAAF.

\subsection{TATB}

TATB is a secondary high explosive, slightly weaker than RDX but stronger than TNT. It is extremely insensitive to shock, vibration, fire or shock. The possibility of accidental detonation is very small, even under severe conditions, so this explosive can be used for applications that require extreme safety, such as explosives in nuclear weapons where accidental detonation would pose an extreme danger. All British nuclear warheads use TATB-based explosives in their primary phase.

Some explosive formulations based on HMX, TATB and KeL-F were characterized for density, VOD (velocity of detonation), initiation sensitivity, ignition temperature and other explosive properties. At a density of $1.80 \mathrm{~g} / \mathrm{cm}^{3}$, the TATB has a detonation velocity of $7350 \mathrm{~m} / \mathrm{s}$. It decomposes without melting at $350{ }^{\circ} \mathrm{C}$, and is stable at temperatures up to $250{ }^{\circ} \mathrm{C}$ even over a long period of time. Pure TATB has a light yellow color and is insoluble in most solvents [2].

\subsection{Fox -7}

Fox-7 or DADNE is a candidate for use as an insensitive explosive. This molecule has attracted attention due to its insensitivity to external impulses and its performance comparable to RDX and HMX, while its sensitivity to shock and friction is much lower than that of RDX and other nitramines. There are three different pathways of FOX-7 synthesis beeing developed, all involving nitration of the heterocyclic compound followed by hydrolysis to give FOX-7. Nitration is performed with mixed acid (sulfuric or nitric acid) at low temperature $\left(<30{ }^{\circ} \mathrm{C}\right)$, and hydrolysis can be performed by isolating the intermediate and hydrolyzing with aqueous ammonia or by adding an acidic mixture of the nitrated intermediate with water[2]. Some properties of FOX-7 compared to the properties of RDX are given further in Table 1. Table 1.shows that the FOX-7 is much less sensitive to shock and shock than the RDX, and is very insensitive to friction. The detonation properties are comparable to RDX. Because of all of the above, the FOX-7 can be considered an attractive alternative to the RDX.

Table 1. Properties of FOX-7 (calculations with Cheetah 1.40) and comparison with RDX[2]

\begin{tabular}{|l|c|c|}
\hline \multicolumn{1}{|c|}{ Property } & FOX-7 & RDX \\
\hline BAM impact sensitivity $(\mathrm{Nm})$ & $>15$ & 7.4 \\
\hline Petri friction sensitivity $(\mathrm{N})$ & $>200$ & 120 \\
\hline Deflagration temperature $\left({ }^{\circ} \mathrm{C}\right)$ & $>240$ & 230 \\
\hline Density $\left(\mathrm{g} / \mathrm{cm}^{3}\right)$ & 1.885 & 1.816 \\
\hline Formation energy (calculated)(kJ/mol) & -118.9 & 92.6 \\
\hline Detonation velocity $($ calculated $)(\mathrm{m} / \mathrm{s})$ & 9040 & 8930 \\
\hline Detonation pressure $(\mathrm{GPa})$ & 36.04 & 35.64 \\
\hline
\end{tabular}




\subsection{Fox-12 (GUDN)}

Energy dinitramides are high-energy materials that can be used for the purposes of synthesizing lowsensitivity ammunition. N-guanylurea dinitramide (GUDN or FOX-12) is a stable salt of dinitramidic acid that has good thermal stability and low solubility in water, has good resistance to mechanical shocks and as such is used in the application of insensitive energy materials [3].

Its thermal stability is comparable to RDX and superior to ammonium dinitramide (ADN). FOX 12 can be used for casting as with LOVA (low vulnerable ammunition) fuels. In addition to the advantages of low sensitivity Fox-12 burns at low temperatures, important in automatic rifles due to the erosion of barrels.

The effect of FOX-12 was assessed by thermochemical calculations. These calculations were based on density $\left(\rho=1.7545 \mathrm{~g} / \mathrm{cm}^{3}\right)$ and heat of formation $(\Delta \mathrm{Hf}=-355.64 \mathrm{~kJ} / \mathrm{mol})$. The results are shown in Table 2 . The density, detonation velocity, and detonation pressure for FOX 12 are between the density values of TNT and RDX. Replacing RDX with FOX 12 in the RDX / TNT 60/40 composition causes a decrease in density and a consequent decrease in detonation velocity and pressure[3].

Table 2. Calculated characteristics [4]

\begin{tabular}{|l|c|c|c|}
\hline \multicolumn{1}{|c|}{ Explosive } & $\begin{array}{c}\text { Density } \\
\left(\mathbf{g} / \mathbf{c m}^{\mathbf{3}} \mathbf{)}\right.\end{array}$ & $\begin{array}{c}\text { Detonation velocity } \\
\mathbf{( m / \mathbf { s } )}\end{array}$ & $\begin{array}{c}\text { Detonation } \\
\text { pressure (GPa) }\end{array}$ \\
\hline FOX-12 & 1.75 & 8210 & 25.7 \\
\hline TNT & 1.65 & 6900 & 19.6 \\
\hline RDX & 1.81 & 8940 & 34.7 \\
\hline FOX-12/TNT (60/40) & 1.61 & 7650 & 23.3 \\
\hline RDX/TNT (60/40) & 1.74 & 8050 & 28.1 \\
\hline
\end{tabular}

\subsection{TEX}

TEX is a derivative of the powerful and very sensitive CL-20 explosive. Unlike the CL-20, the TEX is insensitive to friction, has low impact sensitivity and has a low impact sensitivity and a large critical diameter, which makes it an interesting explosive charge for insensitive ammunition. TEX has a crystal density of 1.99 $\mathrm{g} / \mathrm{cm}^{3}$, the highest density of all nitramine explosives. The high density is due to its isovurtzitan structure, which has a tightly packed crystal lattice, and nitro groups occupy the free space between the cages. TEX is a very energetic material (due to the tense structure of the cage) that has a good combination of high detonation velocity with low sensitivity to mechanical stimuli and good thermal stability. The insensitive nature of TEX suggests that it could be a suitable alternative to TATB, NTO and RDX high performance explosives [5].

\subsection{NTO}

NTO is an insensitive highly explosive material, a potential substitute for RDX in explosive formulations. Although its performance is slightly lower than that of RDX, NTO is more thermally stable and less sensitive to external influences. NTO has performance levels close to RDX levels and its insensitivity is comparable to TATB. Its thermal stability is also high and it decomposes exothermically to about $272{ }^{\circ} \mathrm{C}$. The pressure in NTO and cast explosives show superior mechanical and thermal properties and are insensitive[6].

\subsection{RSS-RDX}

RDX is sensitive to mechanical stimuli such as shock and friction. In recent years, it has been dedicated to the development of RDX in another form, with reduced shock sensitivity RDX (RSS-RDX) or insensitive RDX (insensitive RDX or I-RDX). When this explosive is incorporated into a molded polymer explosive PBX-109, it can reduce impact sensitivity [7]. It is important to note that I-RDX and conventional RDX do not differ in chemical, physical, and safety characteristics, and even raw impact sensitivity tests. I-RDX and conventional RDX can be produced in the same particle size distribution ranges. Differences between I-RDX and 
conventional RDX are visible in the impact sensitivity characteristics of cast PBX compositions. It was also observed that the use of I-RDX does not change any properties of PBX (such as aging, reaction to thermal stimuli, etc.), but only the properties of sensitivity to shock [8].

\subsection{ANTA and DAAF}

ANTA is an amino-nitro-heterocyclic compound used in the use of IM due to the high heat of formation. It can also be said that the insensitive energy material with a density of $1.81 \mathrm{~g} / \mathrm{cm}^{3}, 228{ }^{\circ} \mathrm{C}$ melting point, 225.2 $\mathrm{kJ} / \mathrm{mol}$ heat of formation and performance is slightly lower than TATB [6].

DAAF is also an insensitive explosive that has good resistance to mechanical stimuli and characteristics similar to those of TATB. With its characteristics such as density $1.747 \mathrm{~g} / \mathrm{cm}^{3}$, heat of formation 443.5 $\mathrm{kJ} / \mathrm{mol}$, impact sensitivity $\mathrm{h}_{50 \%}>320$ makes it suitable for use in boosters [9].

\section{Technical requirements for IM (Insensitive Munitions)}

In fact, the potential to develop energetic materials with IM properties is not limited to new materials. The sensitivity of well-established energetic materials can be reduced through various material improvements, such as better crystal quality, reducing crystal or molecular defects, eliminating voids, chemical impurities or the existence of multiple phases. Properties that are advantageous for IM systems include the following [10]: high decomposition temperature; low impact and friction sensitivity; no phase transitions when the substance is subjected to rapid volume expansion or contraction; no autocatalytic decomposition; spherical crystal morphology; good adhesion of the binder matrix; no voids brought about by solvent or gas bubbles; phase purity. Performance characteristics and IM properties of various materials are given in Table 3.

Table 3. Performance characteristics of explosive components and example formulations [11]

\begin{tabular}{|l|c|c|c|c|c|c|c|}
\hline \multicolumn{1}{|c|}{ Properties } & RS-RDX & FOX-7 & GUDN & NTO & TEX & DAAF & TATB \\
\hline Decomposition temperature $\left({ }^{\circ} \mathrm{C}\right)$ & 238,8 & 260 & 217 & 272 & $>250$ & 249 & $>350$ \\
\hline Melting point $\left({ }^{\circ} \mathrm{C}\right)$ & 206 & 254 & no & 270 & 299 & 255 & 330 \\
\hline Oxygen balance $(\%)$ & -21.6 & -21.6 & -19.1 & -24.6 & -42.7 & -22.64 & -55.8 \\
\hline Detonation pressure $(\mathrm{GPa})$ & 34.1 & 33.7 & 25.7 & 349 & 365 & 306 & 300 \\
\hline Velocity of detonation $(\mathrm{m} / \mathrm{s})$ & 8750 & 9090 & 8210 & 8500 & 8560 & 7930 & 8100 \\
\hline Impact senisivity $(\mathrm{cm})$ & 39 & 126 & $>49$ & 87 & 170 & $>320$ & 170 \\
\hline Friction sensivity $(\mathrm{N})$ & 160 & 360 & $>335$ & 360 & 490 & $>360$ & $>360$ \\
\hline$\Delta$ Hf-heat of formation $(\mathrm{kJ} / \mathrm{mol})$ & 16 & -133.9 & -355 & -129.4 & -445.6 & +443.35 & -140 \\
\hline Density $\left(\mathrm{g} / \mathrm{cm}^{3}\right)$ & 1.82 & 1.87 & 1.75 & 1.93 & 1.99 & 1.74 & 1.93 \\
\hline
\end{tabular}

\section{Tests and standards for insensitive ammunition}

The primary purpose of IM testing is to determine the response of ammunition to unplanned stimuli when tested under certain conditions. This information is then used to determine compliance with national IM policies. System security testing conducted 50 years ago in the United States has become the foundation of today's IM testing standards. In 1964, the US Navy established a safety directive for the WR-50 system for registering warhead vulnerabilities and certain security features [12]. This included a fast and slow cook-off test and a reaction to a projectile impact. Following the establishment of the IM program in the United States, requirements for IM tests were also introduced. Requests for testing also followed in the international community through the NATO program. NATO established IM principles and technical requirements in 1995, and in 2003 the USA incorporated NATO technical requirements into MIL-STD-2105C [13]. The test requirements are defined via individual STANAGs. The number of tests and testing practices varies from country to country, but most IM testing programs are based on NATO STANAG 4439 Edition 2 (Policy for introduction and assessment of insensitive ammunition (IM)) and AOP-39 (Guidance on the Assessment and Development of Insensitive Munitions (IM)) edition 2 [14]. For each of the six tests defined in AOP-39, there 
is a standard test designed to classify ammunition based on the type of response. Those six tests and their performance are [15] :

1. Slow Cook-off - This requirement specifies a slow warming test that may result from a fire in an adjacent magazine, premises, or vehicle. These types of incidents require exposure to a gradually increasing thermal environment at a rate of $3.3^{\circ} \mathrm{C} / \mathrm{h}$.

2. Fast Cook-off - The requirement to investigate the danger of rapid warming comes from a liquid fuel fire, such as burning aviation fuel on a flight deck or burning diesel fuel from a truck as a result of a car accident. Therefore, these types of incidents require the test sample to be exposed to heat fluxes in a burning flame of a burning fuel.

3. Sympathetic Detonation - The purpose of this test is to subject one or more packages of ammunition to the effects of the worst case scenario, is to detonate an identical package of ammunition under conditions that are most likely to result in a sympathetic reaction. The purpose is to determine the sympathetic response of ammunition sensitivity and ultimately to provide information on the effectiveness of the safety barriers used to separate a single, packaged, or multiple ammunition package.

4. Multiple Bullet Impact - This requirement describes the examination of the danger of ammunition strikes from small arms during terrorist or combat events. The aim of this test is to provide a standard test procedure for assessing the reaction of ammunition to the impact of a triple burst of M2 machine gun, caliber $12.7 \mathrm{~mm}$, AP ammunition (armor-piercing).

5. Multiple Fragment Impact - The request for testing comes from combat or terrorist events that use artillery missiles or improvised explosive devices for attacks. To predict the response of ammunition to these types of events, the test sample is subjected to the impact of a calibrated high-speed fragment representing fragments of a bomb or fragments formed from artillery grenades.

6. Shaped Charge Jet Impact Testing - This test is performed due to possible damage or unwanted reaction of ammunition when using missiles, guided weapons or air bombs. The test is performed by subjecting the ammunition to a direct impact of a cumulative shaped charge jet and monitoring their reaction. It is also preferred that the diameter of the detonation be larger than the diameter of the jet so that the test can be performed.

\section{Chemical and thermal stability of IM}

\subsection{Chemical stability}

An energetic material may undergo chemical reaction in response to shock, thermal, or chemical insults. In this review, we concentrate on stability to shock excitation. It is often the case, however, that a material's stability to various forms of loading is highly correlated with one another. Energetic materials exist in a higher energy state than their lowest energy decomposition products. Thus energetic molecules are often termed metastable.

Recently, several metastable nitrogen and oxygen compounds have been proposed that contain novel bonding. This has led to recent theoretical studies of hypothetical systems as high-energy density materials (HEDM), such as oxygen ring-strained systems (O4 and O8), tetrahedral N4, and cubic N8. The dissociation energy of the weakest bond of an explosive molecule plays an important role in initiation events. However, the correlation between bond strength and impact sensitivity is not general, but is limited within a particular class of molecules. Given the complexity of the chemistry of detonation of explosives, it is not surprising that the energy of dissociation of bonds alone is not sufficient to explain the sensitivity of explosives [16].

It can be seen from Table 3. that there is some correlation between the dissociation energy of the $D_{e}$ bond and the sensitivity of the explosives. Nitrobenzene compounds with the highest $\mathrm{D}_{\mathrm{e}}$ values are the least sensitive. The correlation between De and Ed could be an important quantity in determining the impact sensitivity of molecules[16]. 
Table 3. Bond strength (De) of the weakest bond, energy content (Ed, $\mathrm{kJ} / \mathrm{cc})$, impact sensitivity $\mathrm{H}_{50}(\mathrm{~cm})[16]$

\begin{tabular}{|c|c|c|c|c|}
\hline Material & Weakest bond & $D_{\mathrm{e}}(\mathrm{kJ} / \mathrm{mol})$ & $E_{d}(k J)$ & $\mathrm{H}_{50}(\mathrm{~cm})$ \\
\hline TATB & $\mathrm{C}-\mathrm{NO}_{2}$ & 323 & 8.6 & $>320$ \\
\hline DATB & $\mathrm{C}-\mathrm{NO}_{2}$ & 312 & 8.6 & $>320$ \\
\hline TNA & $\mathrm{C}-\mathrm{NO}_{2}$ & 300 & 8.1 & 177 \\
\hline TNT & $\mathrm{C}-\mathrm{NO}_{2}$ & 261 & 7.7 & 148 \\
\hline HMX & $\mathrm{N}-\mathrm{NO}_{2}$ & 179 & 11.1 & 32 \\
\hline RDX & $\mathrm{N}-\mathrm{NO}_{2}$ & 174 & 10.4 & 28 \\
\hline TNAZ & $\mathrm{C}-\mathrm{NO}_{2}$ & 167 & 11.229 & 29 \\
\hline NTO & $\mathrm{C}-\mathrm{NO}_{2}$ & 284 & 7.7 & $>280$ \\
\hline TETRYL & $\mathrm{C}-\mathrm{NO}_{2}$ & 120 & 8.8 & 37 \\
\hline TNB & $\mathrm{C}-\mathrm{NO}_{2}$ & 283 & 8.6 & 100 \\
\hline EDNA & $\mathrm{N}-\mathrm{NO}_{2}$ & 207 & 9.2 & 35 \\
\hline HNB & $\mathrm{C}-\mathrm{NO}_{2}$ & 183 & 14.3 & 8,5 \\
\hline DINGU & $\mathrm{N}-\mathrm{NO}_{2}$ & 180 & 8.5 & 24 \\
\hline PETN & $\mathrm{O}-\mathrm{NO}_{2}$ & 167 & 10.5 & 14 \\
\hline $\mathrm{N}$ & $\mathrm{N}-\mathrm{NO}_{2}$ & 157 & 10.0 & 20 \\
\hline
\end{tabular}

From an analysis of the structures of thermally stable explosives, it appears that there are four general approaches to impart thermal stability to explosive molecules [17]:

- introduction of amino groups;

- condensation with a triazole ring;

- salt formation;

- introduction of conjugation.

\section{Detonation Performance Analyses for Recent Energetic Molecules}

In order to assess the potential of new high-energy materials, their energy characteristics must be compared with those of modern materials. One of the programs used to predict IM performance is Jaguar's computer program, which provides accurate estimates for the detonation and performance of an explosive if precise data on its density and heat of formation are known. This post-assessment data is used to compare performance against already known energy materials such as TNT, RDX, HMX and CL-20. The detonation properties of the known compounds obtained by the Jaguar model have deviations of about 2-3\% compared to the experimental results. The predicted values of the C-J velocities, temperatures, and pressures, Gurney velocities at 3 and 7 area expansions, and limiting energies are presented in Table 4.[18].

Table 4. Jaguar predicted detonation properties[18]

\begin{tabular}{|c|c|c|c|c|c|c|c|c|}
\hline Explosive & $\begin{array}{l}\text { Density } \\
\left(\mathrm{g} / \mathrm{cm}^{3}\right)\end{array}$ & $\begin{array}{c}\Delta \mathbf{H}_{\mathrm{f}} \\
(\mathrm{kJ} / \mathrm{mol})\end{array}$ & $\begin{array}{c}\text { Det. } \\
\text { velocity } \\
(\mathrm{km} / \mathrm{s})\end{array}$ & $\begin{array}{c}\text { C-J } \\
\text { Pressure } \\
\text { (GPa) }\end{array}$ & $\begin{array}{c}\text { C-J } \\
\text { Temp. } \\
(\mathrm{K}) \\
\end{array}$ & $\begin{array}{c}\text { Gurney } \\
\text { velocity } \\
(\mathrm{km} / \mathrm{s})\end{array}$ & $\begin{array}{c}\text { Boundary } \\
\text { energy } \\
\mathrm{E}_{0}\left(\mathrm{~kJ} / \mathrm{cm}^{3}\right)\end{array}$ & $\begin{array}{c}\text { Oxygen } \\
\text { balance } \\
(\%) \\
\end{array}$ \\
\hline CL-20 & 2.044 & 376.6 & 9.79 & 45.6 & 4035 & 2.88 & -13.07 & -11 \\
\hline TNAZ & 1.832 & 11.8 & 8.73 & 35.1 & 4224 & 2.77 & -11.49 & 16.7 \\
\hline HMX & 1.905 & 75 & 9.09 & 38.7 & 3514 & 2.76 & -11.38 & -21.6 \\
\hline RDX & 1.816 & 70 & 8.76 & 34.8 & 3708 & 2.73 & -10.88 & -21.6 \\
\hline TNT & 1.654 & -63 & 6.89 & 19.8 & 3092 & 2.20 & -7.11 & -74 \\
\hline TATB & 1.937 & -140 & 8.778 & 31.8 & 2393 & 2.12 & -7.78 & -55.6 \\
\hline FOX-7 & 1.885 & -133.9 & 8.80 & 35 & 2917 & 2.554 & -9.35 & -21.6 \\
\hline TEX & 1.99 & -445.6 & 8.51 & 32.7 & 2631 & 2.26 & -8.83 & -40.4 \\
\hline DAAF & 1.747 & 443.35 & 8.16 & 28.2 & 3155 & 2.44 & -8.23 & -52.8 \\
\hline NTO & 1.93 & -129.4 & 8.64 & 32.7 & 2389 & 2.25 & -7.34 & -24.6 \\
\hline
\end{tabular}




\subsection{C-J and Gurney velocity comparisions for energetic compounds}

The results obtained by the Jaguar model from Table 4. require some accuracy checking in the form of a comparison of the experimental detonation and the Gurney velocity with the values obtained from the Jaguar model and the analytical model of the cylinder. Table 5 shows a slight deviation in the results. NTO and DAAF values and their formulation with HMX, RDX, Viton were taken for experimental velocities [18].

Table 5. NTO and DAAF formulations[18]

\begin{tabular}{|l|c|c|c|c|}
\hline \multirow{2}{*}{ Explosive } & \multirow{2}{*}{ wt (\%) } & Density $\mathbf{( g / \mathbf { c m } ^ { \mathbf { 3 } } )}$ & $\begin{array}{c}\mathbf{D}_{\mathbf{e x p}} \\
(\mathbf{k m} / \mathbf{s})\end{array}$ & $\begin{array}{c}\mathbf{D}_{\text {Jaguar }} \\
(\mathbf{k m} / \mathbf{s})\end{array}$ \\
\hline \multirow{3}{*}{ NTO } & & 1.87 & 8.22 & 8.38 \\
\cline { 3 - 5 } & \multirow{2}{*}{100} & 1.86 & 8.20 & 8.31 \\
\cline { 3 - 5 } & & 1.83 & 8.09 & 8.18 \\
\cline { 3 - 5 } & & 1.80 & 8.02 & 8.07 \\
\hline DAAF & 100 & 1.685 & 7.93 & 7.93 \\
\hline DAAF/RDX/VITON & $80 / 15 / 5$ & 1.66 & 7.76 & 7.70 \\
\hline DAAF/NTO/VITON & $60 / 35 / 5$ & 1.67 & 7.91 & 7.83 \\
\hline
\end{tabular}

For the initial density of the FOX-7/Viton (95/5) mixture, the obtained Gurney velocities with the Jaguar and the analytical model of the cylinder show a very small deviation from the experimental values, the illustration of which is given in Figure 1. [18].

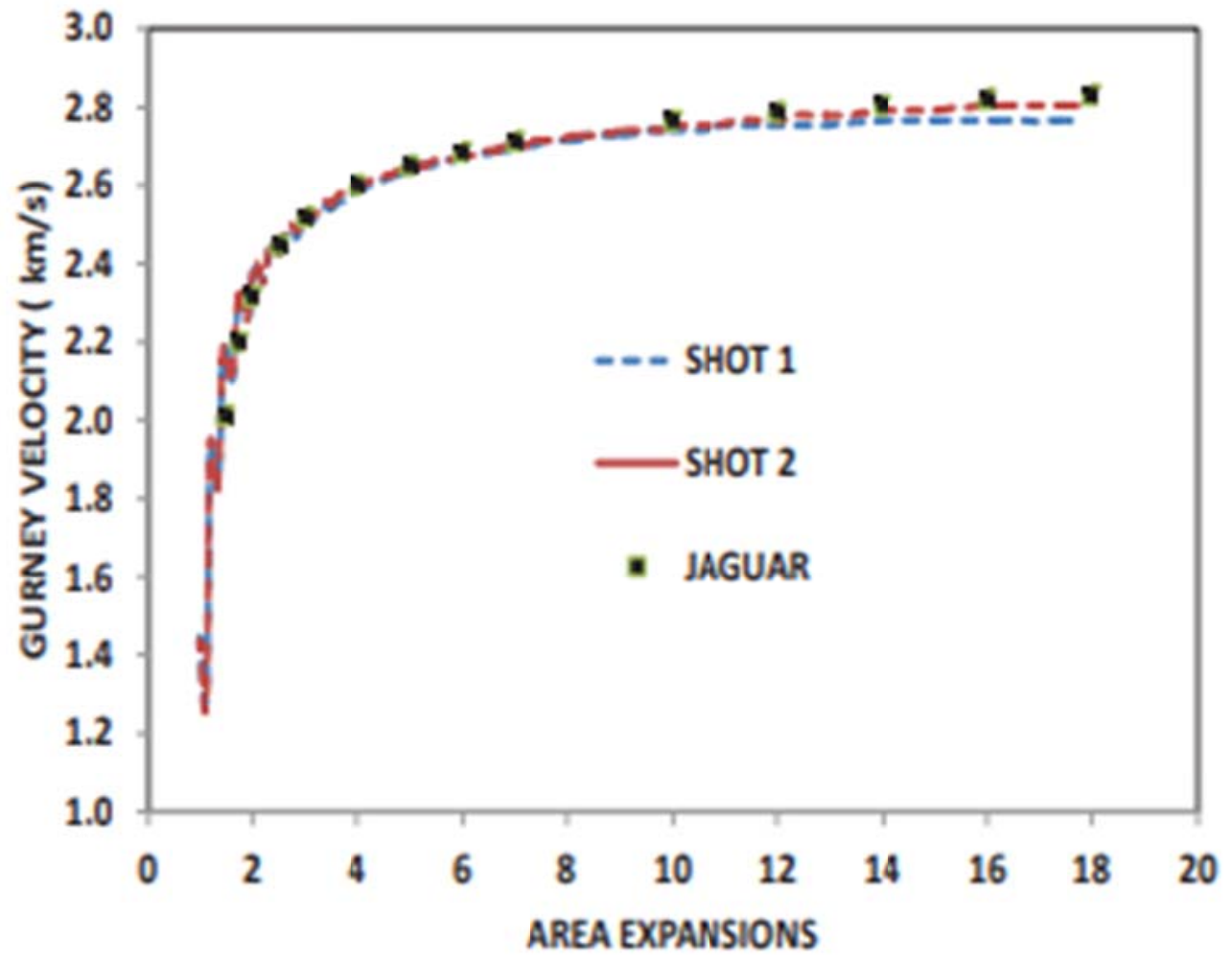

Figure 1. Gurney velocity change for FOX-7 / Viton explosive at a density of $1.945 \mathrm{~g} / \mathrm{cm}^{3}$ [18]

Figure 2 shows a very small deviation of the calculated Gureny speed with Jaguar and the analytical model of the cylinder from the experimental values for the mixture of DNMT/HMX formulation (49.5/50.5) at an initial density of $1.725 \mathrm{~g} / \mathrm{cm}^{3}[18]$.

The analyses provide insight into the detonation behavior and performance of the new available high-energy low-sensitivity explosives. Jaguar has proven to be a method that is consistent with experimentally derived results for most high-energy materials. 


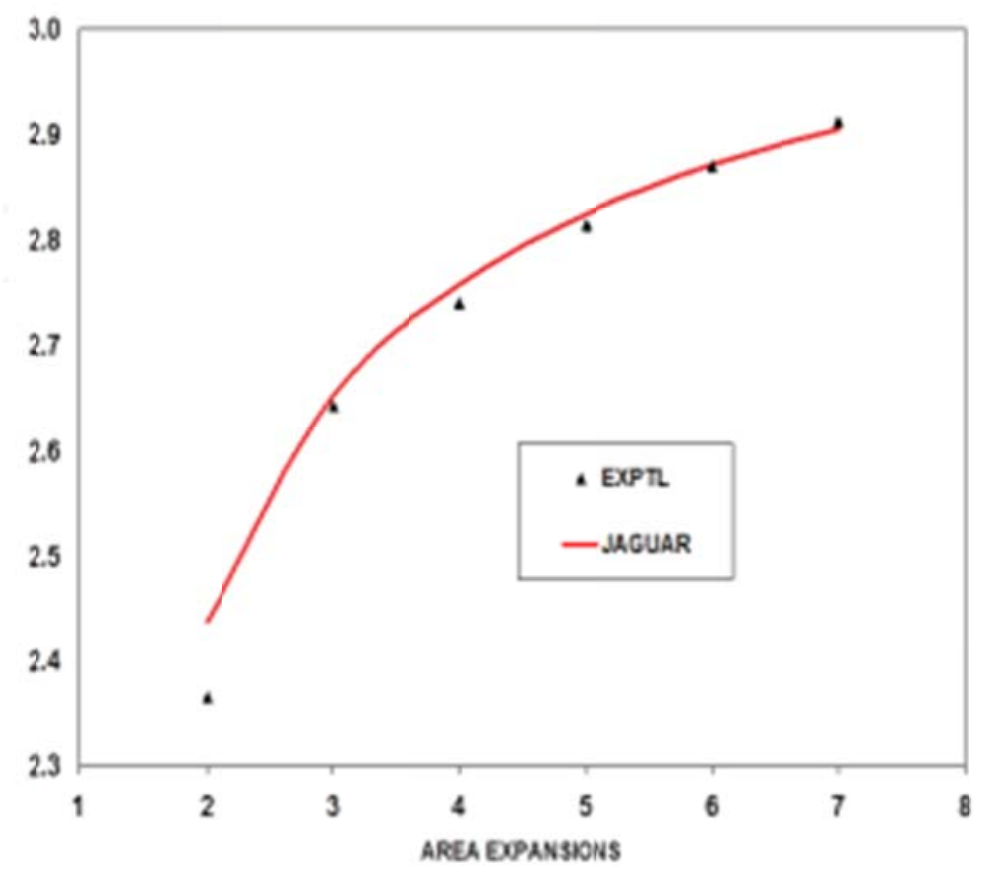

Figure 2. Gurney velocity change for DNMT/HMX explosives at a density of $1.725 \mathrm{~g} / \mathrm{cm}^{3}[18]$

\subsection{Predicting detonation velocity using Cheetah 1.40}

Predicting the density and heat of formation can provide insight into the possible performance of high-energy materials. The results of a study of one such prediction are shown in Figure 3. [19]. The calculated detonation velocities of several explosives are presented using two different ways of using the Cheetah 1.40 program, namely the thermochemical code and using the BKWC library (Backer-Kistiakowski) Wilson/Cheetah at full crystal density [20]:

- the first set of data, the calculated detonation velocity was based on the experimental heat of formation and density.

- second set of data, the calculated detonation velocity was based on the theoretically predicted heat of formation and density.

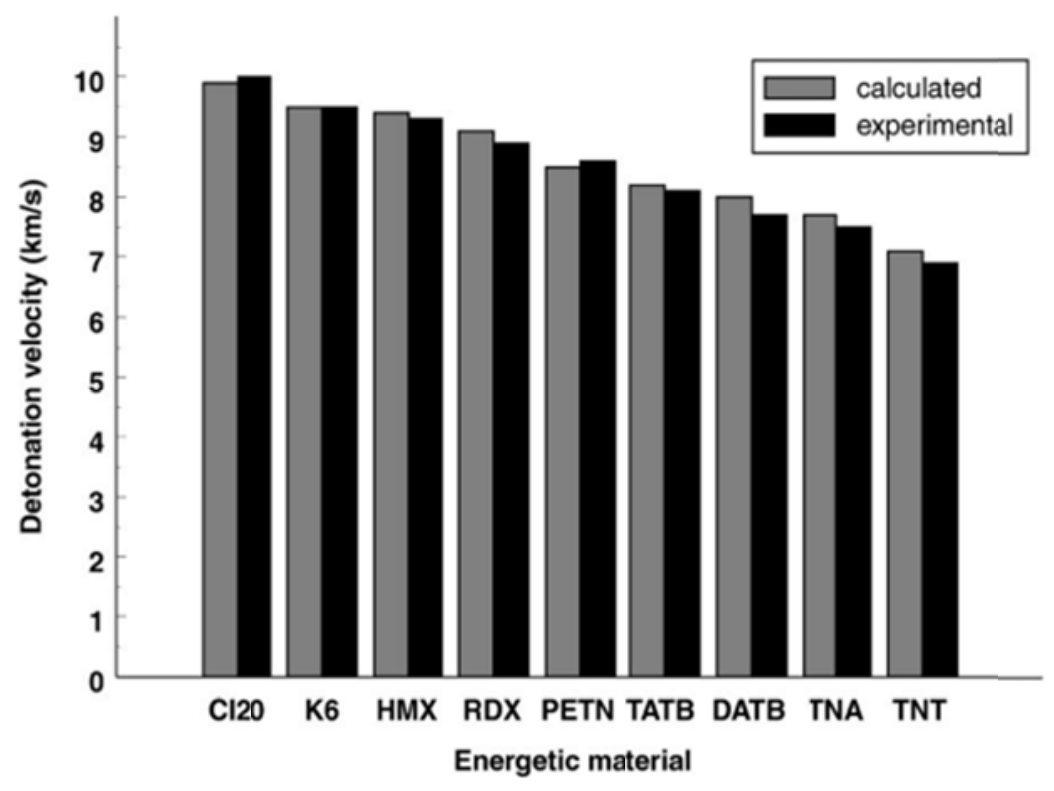

Figure 3. Detonation velocities predicted by Cheetah $1.40[20]$ 


\section{Conclusion}

No explosive molecule has all the desired properties from a high efficiency and low sensitivity perspective. In a constant effort to optimize desirable properties such as insensitivity to stimuli and shocks (shock, spark and friction), as well as high thermal stability and small critical diameter, various energy materials and material mixtures are constantly researched and developed.

The main disadvantages of current conventional explosives such as those based on RDX and HMX are the relatively high impact sensitivity and moderately high handling sensitivity. However, their advantage is small critical diameter and high performance. With materials that are the basis of low-sensitivity ammunition, there is a compromise for lower performance and higher critical diameter, but impact sensitivity is reduced and sensitivity in handling is almost eliminated.

Insensitive ammunition (IM) is defined as ammunition that reliably meets its performance, readiness and operational requirements when needed, but minimizes violent reactions and subsequent collateral damage when exposed to unplanned stimuli.

Testing is a vital component of any national IM program. Hazards and threats to high-energy materials are either thermal events or caused by shock and shock. The international community has established requirements for testing and testing the insensitivity of materials, developing six unique tests representing these events. There are two basic documents that provide guidelines for IM testing. STANAG 4439 (NonSensitive Ammunition Introduction and Assessment Policy), lists all STANAG tests that provide requirements and provide guidance for individual IM tests. Additional information can be found in AOP-39 (Guidelines for the Assessment and Development of Non-Sensitive Ammunition). This document includes test requirements, test protocols, a list of response descriptions, and an assessment methodology for IM coding.

Thermochemical calculation methods have been developed to predict the properties of new materials. The detonation properties of the known compounds can be calculated with deviations of about 2-3\% from the experimental results. In the future, it is expected that a wider range of energy materials will be able to be adapted to specific purposes.

Many new low-sensitivity energy materials are still in the experimental phase. Their production costs are very high, which is currently a limiting factor for their use. Therefore, it is necessary to make an effort to make their production profitable.

\section{References}

[1] R. Meyer, J. Kohler, Explosives, 4th revised and extended ed., VCH Publishers, Weinheim, New York, 1993.

[2] Dilip M. Badgujar, Mahadev B. Talawar, Pramod P. Mahulikar, High Energy Materials Research Laboratory, Pune-411021, India 2 School of Chemical Sciences, North Maharashtra University, Jalgaon-425001, India.

[3] H.Östmark, U.Bemm, H.Bergman,A.Langlet, "N-Guanylurea-Dinitramide: A New Energetic Material with Low Sensitivity for Propellants and Explosives Applications", Termochimica Acta, 384, 253-259, 2002.

[4] H.Oestmark, A.Helte, T. Carlsson, "N-guanylurea-dinitramide (FOX-12): A new extremely insensitive energetic material for explosive application". Proceedings of the 13th International Detonation Symposium, 121-127, 2007.

[5] E. Koch, "TEX-4,10-Dinitro-2,6,8,12-tetraoxa-4,10-diazatetracyclo - dodecane - Review of a Promising High Density Insensitive Energetic Material”. Propellants, Explosives, Pyrotechnics, 40 (3): 374-387, 2015.

[6] J. P. Agrawalt, Physics and Chemistry of Solids, Cavendish Laboratory, University of Cambridge, Cambridge. U.K. 
[7] P.F. Pagoria, A.R. Mitchell, R.D. Schmidt, R.L. Simpson, F. Garcia, J. Forbes, J. Cutting, R. Lee, R. Swansiger, D.M. Hoffman, Presented at the Insensitive Munitions and Energetic Materials Technology Symposium, San Diego, CA, 1998.

[8] A.Freche, J.Aviles, L. Donnio, C.Spyckerelle, Insensitive RDX (IRDX), Insensitive Munitions and Energetic Materials Symposium - Technology Implementation in the 21st Century, San Antonio, Texas, 2000 .

[9] T.Han, P.Pagoria, A.Gash, A.Maiti, C.Orme, A.Mitchell, L. Fried, "The Solubility and Recrystallization of 1,3,5-Triamino-2,4,6-trinitrobenzene in a 3-Ethyl-1-methylimidazolium Acetate-DMSO Co-solvent System”. New J. Chem., 33, 50, 2009.

[10] H.R.Bircher, P. Mäder, J. Mathieu, "Properties of CL-20 based high explosives", In: Proc. 29th Int. Annual Conference of ICT, Karlsruhe, 94, 1994.

[11] A.Pillai, M.Joshi, A.Barve, S.Velapure, J.Karir, "Cellulose Acetate BinderBased LOVA Gun Propellant for Tank Guns”. Def. Sci. J., 49(2): 141-149., 1995.

[12] R. Beauregard, "History of the US Navy's IM Program", January 2005.

[13] MIL-STD-2105C: Hazard Assessment Tests for Non-Nuclear Munitions, July 2003.

[14] STANAG 4439, Edition X, "Policy For Introduction And Assessment Of Insensitive Munitions", November 2018. AOP-39, Edition 3, "Guidance On The Assessment And Development Of Insensitive Munitions",March 2010.

[15] Afanosev, C.; Bobolev, U. "Initiation of Solid Explosives by Impact". Israel Program of Scientific Translations, Jerusalem 1971.

[16] L. E. Fried, M. R. Manaa, P. F. Pagoria, R. L. Simpson Energetic Materials Center, Chemistry and Materials Science Directorate, Lawrence Livermore National Laboratory, P. O. Box 808, Livermore, California 94551.

[17] J. P. Agrawalt, Physics and Chemistry of Solids, Cavendish Laboratory, University of Cambridge, Cambridge. U.K.

[18] https://doi.org/10.1063/1.5044989

[19] L. E.Fried, M. R.Manaa, P. F.Pagora, R. L.Simpson, "Design and synthesis of energetic materials". Annu Rev Mater Res., 31, 291-321, 2001

[20] L. E. Fried, P. C. Souers, "BKWC: An Empirical BKW Parametrization Based on Cylinder Test data", Propellants, Explosives, Pyrotechnics, 21,215-23, 1996. 